\title{
Pengembangan Internet of Things Pada SMart City
}

\author{
Agung Ahmad ${ }^{1}$, Budi Solihin ${ }^{2}$ \\ Jurusan Teknik Informatika \\ UIN Jakarta \\ aa ahmad@gmail.com ${ }^{1}$, busro77@gmail.com²
}

\begin{abstract}
Smart city is an advanced urban area that excels in the fields of economy, government, people and life through strong human capital, social capital and ICT infrastructure. This is a new approach to managing the complexity of city life, increasing efficiency, reducing costs and improving the quality of life of citizens. This paper is about potential smart city applications as applied to the domains of intelligent transportation, intelligent tourism and recreation, smart health, ambient assistance, crime prevention and community safety, governance, monitoring and infrastructure, disaster management, environmental management, garbage collection and sewer management, smart homes, and smart energy. This smart city application supports the vision of the future of cities, which aims to exploit ICTs, namely the internet of things technologies (IoT), for the provision of value added services. Furthermore, this paper presents technical solutions for energy control and comfort at home for proof of the concept of smart city infrastructure applications. The demonstration described here is about how smart applications can manage energy and comfort control in a room that has a number of people and electrical equipment, with each being a source of heat.
\end{abstract}

Keywords-Internet of Things, smart city

\section{Pendahuluan}

Konsep smart city menyoroti pentingnya ICT untuk meningkatkan profil kota. Sebuah kota dapat disebut 'pintar' ketika investasi dalam modal manusia dan sosial dan infrastruktur komunikasi tradisional dan modern mendorong pertumbuhan ekonomi yang berkelanjutan dan kualitas hidup yang tinggi, dengan pengelolaan sumber daya alam yang bijaksana melalui tata kelola partisipatif (Caragliu, 2011). Kota pintar juga didefinisikan sebagai kota yang menghubungkan infrastruktur fisik, infrastruktur ICT, infrastruktur sosial, dan infrastruktur bisnis untuk meningkatkan kecerdasan kolektif kota (Harrison, 2010). Internet of Things (IoT) dianggap sebagai penelitian utama dan aliran inovasi yang mengarah ke banyak peluang untuk layanan baru dengan menghubungkan dunia fisik dan dunia maya dengan sejumlah besar perangkat elektronik yang didistribusikan di rumah, kendaraan, jalan, bangunan, dan banyak lingkungan publik lainnya (Moreau , 2012). Perkotaan IOT dirancang untuk mendukung visi kota cerdas, yang bertujuan untuk memanfaatkan teknologi paling canggih untuk mendukung layanan bernilai tambah bagi administrasi kota dan warganya (Zanella, 2014). Kota pintar di seluruh dunia hidup di bawah 'banjir data' di mana data besar yang dihasilkan oleh orang dan sensor diproses untuk pengambilan keputusan (Molinari, 2014).

Tujuan dari makalah ini adalah untuk menampilkan peran yang dapat dimainkan IoT di kota pintar. Makalah ini dimulai dengan meninjau layanan dan aplikasi yang mendukung kota pintar. Layanan ini termasuk ke dalam domain transportasi cerdas, pariwisata dan rekreasi cerdas, kesehatan cerdas, lingkungan hidup dengan bantuan ambient, pencegahan kejahatan dan keselamatan masyarakat, tata kelola, pemantauan dan infrastruktur, manajemen bencana, manajemen lingkungan, pengumpulan sampah dan pengelolaan saluran pembuangan, rumah pintar dan energi pintar. Akhirnya ini dibuktikan melalui contoh seorang demonstran sebagai bukti konsep konservasi energi dan kenyamanan di sebuah ruangan.

Migrasi pedesaan-perkotaan cenderung berdampak pada pemberian layanan di kota-kota karena sumber daya yang terbatas. Akibatnya, konsep kota pintar telah diadopsi untuk meningkatkan pengiriman layanan di daerah perkotaan. Penelitian ini adalah tentang bagaimana kota dapat 
dikompromikan melalui adopsi IoTs. Sebuah survei literatur dilakukan pada apa yang merupakan kota pintar dan domain apa dari setiap kota yang dapat dibuat pintar melalui adopsi IoT. Domain transportasi, pariwisata, kesehatan, lingkungan hidup yang dibantu, pencegahan kejahatan, tata kelola, manajemen infrastruktur, manajemen bencana, manajemen lingkungan dan manajemen energi diidentifikasi. Melalui sampling literatur, aplikasi IoT untuk berbagai domain ini diidentifikasi. Selain itu, di lingkungan laboratorium, solusi teknis prototipe untuk kontrol energi dan kenyamanan di rumah untuk bukti konsep aplikasi infrastruktur kota cerdas dikembangkan. Demonstran yang dijelaskan di sini adalah tentang bagaimana aplikasi pintar dapat mengelola kontrol energi dan kenyamanan di sebuah ruangan yang memiliki sejumlah orang dan peralatan listrik, dengan masing-masing menjadi sumber panas.

\section{StUdi Literatur}

Bagian ini menawarkan contoh aplikasi kota cerdas untuk transportasi cerdas, energi cerdas, kesehatan cerdas, lingkungan hidup dengan bantuan ambient, pencegahan kejahatan dan keselamatan masyarakat, tata kelola, pemantauan kondisi dan pemeliharaan infrastruktur, manajemen bencana dan keadaan darurat, rumah pintar, pariwisata dan rekreasi dan manajemen lingkungan.

\subsection{Smart Transport}

Sistem transportasi terintegrasi akan membutuhkan satu tiket dalam bentuk kartu pintar yang dapat diisi dengan uang dan digesek pada setiap titik masuk ke sistem transportasi menggunakan teknologi Near Field Communication (NFC) untuk mengirimkan informasi dari kartu ke mesin bacaan dan kembali. Pembayaran dipotong sesuai dari kartu untuk perjalanan yang dilakukan. Di setiap tempat parkir terdapat meteran yang mendeteksi keberadaan mobil yang diparkir melalui tanda di pelat nomor segera setelah mobil memasuki teluk dan mulai menghitung biaya parkir ketika mereka menumpuk. Pengendara mendaftarkan akun etoll dengan biro jalan dan dikeluarkan dengan kartu etoll frekuensi radio (RFID) yang diaktifkan pada mobil. Ketika mobil berjalan di bawah gerbang etoll, detail pengemudi dan detail jarak yang mereka lalui dibaca oleh pembaca kartu di gerbang etoll, dan diteruskan ke server di biro jalan.

\subsection{Smart Tourism}

Sebuah museum telah menambah sistem realitas dengan kode QR yang ditempatkan di titik-titik strategis di museum. Pengunjung menggunakan ponsel pintar untuk mengambil gambar kode QR. Setiap kode QR menghubungkan ponsel ke URL yang memberikan perincian di bagian museum tempat mereka berada.

\subsection{Smart Health}

Aplikasi seluler, sensor jaringan area tubuh dan ekosistem manajemen kesehatan pribadi telah diakui sebagai komponen penting dari platform teknologi generasi perawatan kesehatan berikutnya karena potensi mereka untuk memungkinkan warga memainkan peran aktif dalam pengelolaan kesehatan mereka (Nollo, 2014) . Aplikasi kesehatan seluler (ponsel cerdas dan tablet) dapat terhubung ke perangkat medis atau sensor (misalnya gelang, jam pintar, patch, dll.) Dan memberikan bantuan dan pengingat pribadi. Melalui penggunaan sensor yang terhubung langsung ke perangkat seluler, sekarang mungkin untuk mengumpulkan sejumlah besar data.

\subsection{Lingkungan Hidup dengan Bantuan}

Untuk mendorong lansia agar tinggal di rumah mereka lebih lama dan tidak di panti jompo, mereka memakai sensor tubuh untuk mendeteksi parameter tubuh. Sensor ini terhubung ke pengasuh mereka secara nirkabel. Jika salah satu parameter keluar dari jangkauan, alarm ke pengasuh dipicu. 


\subsection{Pencegahan Kejahatan dan Keselamatan Masyarakat}

Identifikasi penjahat telah dibuat lebih mudah melalui mesin deteksi biometrik mobile. Sidik jari dari seorang tersangka ditangkap ke mesin biometrik genggam polisi. Data ini dikirim melalui jaringan ke database sidik jari yang terletak di Departemen Dalam Negeri untuk perbandingan dan mengembalikan identitas tersangka (Dlodlo, 2013).

\subsection{Pemerintahan}

Jumlah layanan online yang tersedia, tingkat keefektifan dan penggunaan serta tingkat interaksi mereka merupakan indikator penting dari 'tingkat kecerdasan' e-government (Fioroni, 2014). Tagihan air, limbah, listrik, dan tarif masing-masing memiliki tag ID yang dibaca oleh pembaca tag di konter dan secara otomatis dicocokkan dengan detail pengguna dalam database dan diperbarui dengan pembayaran dilakukan.

\subsection{Pemantauan Kondisi dan Pemeliharaan Infrastruktur}

Truk-truk beban berat yang mengangkut kargo melintasi jembatan yang merupakan rute regulernya cenderung menekan jembatan karena beratnya. Sensor yang mendeteksi integritas struktural jembatan melaporkan kepada badan jalan melalui jaringan pribadi pada kesehatan struktural jembatan ketika truk melewati mereka.

\subsection{Manajemen Bencana dan Darurat}

Satelit mendeteksi tanda panas dari api yang baru saja dimulai di suatu daerah. Satelit menyampaikan informasi ke pusat kendali yang mencatat kebakaran di sistem mereka dan mengirimkan truk pemadam kebakaran. Pusat kendali yang sama memicu sirene api yang ditempatkan di titik-titik strategis di daerah itu untuk memperingatkan penduduk.

\subsection{Pengelolaan Lingkungan}

Para insinyur kota memasang sensor di seluruh kota yang mengukur suhu, kelembaban relatif, karbon monoksida, nitrogen dioksida, kebisingan dan partikel. Jika salah satu parameter berada di atas ambang batas yang ditetapkan, sensor yang mengaktifkan GPS mengirim alarm ke simpul pusat. Node pada gilirannya mengirimkan informasi ke ponsel dari penghuni.

\subsection{Menolak Pengumpulan dan Pengelolaan Saluran Pembuangan}

Kota memiliki sensor yang ditempatkan di septic tank sehingga menimbulkan alarm ketika tangki septik mencapai tingkat yang ditentukan. Truk kemudian dikirim untuk membuang limbah dari septic tank. Kotamadya menempatkan sampah di posisi strategis di kota. Tempat sampah memiliki sensor yang meningkatkan alarm ketika tempat sampah penuh dan truk pengumpul sampah dikirim untuk mengumpulkan sampah (Dlodlo, 2012).

\subsection{Rumah Pintar}

Rumah yang kita tinggali dapat dikonfigurasi untuk mengidentifikasi individu, apakah mereka adalah anggota keluarga biasa, tamu, atau orang yang tidak berwenang. Individu diidentifikasi dengan cara apa yang mereka miliki pada orang, misalnya, ponsel pintar yang diidentifikasi melalui gelombang radio. Jika seorang individu di dalam rumah tidak memiliki ID seperti itu maka mereka diidentifikasi sebagai tidak sah dan sinyal alarm disalurkan ke badan eksternal yang relevan atau ke pemilik rumah.

\subsection{Smart Energy}


Aplikasi yang berjalan di ponsel memungkinkan individu untuk mengontrol perangkat listrik rumah dari jarak jauh. Pengguna memilih alat dari aplikasi dan mematikannya. Permintaan untuk menonaktifkan lintasan jaringan GSM ke alamat IP alat rumah (Sensormind, 2015).

\section{ARSITEKTUR}

3.1 Gambaran Umum Penggunaan IR untuk Mengontrol Peralatan

Penelitian dilakukan untuk secara otomatis mengendalikan alat yang biasanya dikontrol dengan menggunakan remote control genggam. Kontroler ini bergantung pada radiasi inframerah (IR) untuk komunikasi dengan alat. Di sini, sebuah dioda pemancar cahaya (LED) IR pada pengendali jarak jauh mengirimkan informasi yang diambil oleh penerima IR dalam alat. Awalnya, modul IR pada alat menerima sinyal infra merah dari pengendali jarak jauh, mendemodulasi dan mengeluarkan kode yang diterima ke mikrokontroler yang ditanamkan dalam peranti. Kode yang diterima ini memicu sirkuit logika dalam alat setiap kali tombol remote control ditekan.

Untuk secara otomatis mengontrol alat menggunakan sinyal IR, kami memasukkan rangkaian yang berisi mikrokontroler. Mikrokontroler ini menjalankan pustaka IR yang menerima dan mengirim kode jauh IR dalam beberapa protokol. Untuk mengendalikan alat dengan LED IR yang terhubung ke mikrokontroler, protokol yang digunakan oleh alat harus diketahui oleh mikrokontroler. Ini dilakukan sebagai berikut: Menggunakan remote control alat, penerima IR menafsirkan data yang dihasilkan dari penekanan tombol jarak jauh, menyalinnya ke mikrokontroler dan kemudian mengirimkannya ke IR LED untuk transmisi bila diperlukan. Karena protokol berbeda dari pabrikan ke pabrikan, pabrikan alat harus diatur untuk menggunakan pustaka dengan benar pada mikrokontroler.

Oleh karena itu langkah-langkah yang diperlukan adalah:

- Dapatkan kode IR dari kendali jarak jauh yang ada,

- Cantumkan kode IR ini ke mikrokontroler mis. Arduino,

- Saat diperlukan, mikrokontroler mentransmisikan kode melalui LED IR untuk menjalankan alat,

- Penerima IR pada alat menerima kode, dan

- Alat ini melakukan tindakan yang diperlukan

\subsection{Mengontrol Air Conditioner di Kamar}

Salah satu fitur dari kota pintar adalah kontrol optimal konsumsi energi di rumah sambil tetap memberikan kenyamanan pada suhu yang ideal. Metode untuk menjaga kenyamanan di rumah adalah dengan menyesuaikan suhu melalui AC. Arsitektur sistem ini adalah eksperimen dalam menyediakan suhu yang tepat untuk kenyamanan optimal dalam lingkungan ruangan yang disimulasikan. Ini menggabungkan berbagai sensor untuk mendeteksi apakah orang-orang berada di ruangan, apakah jendela atau pintu terbuka atau tertutup, dan apakah AC harus dinyalakan atau dimatikan untuk mempertahankan suhu yang ideal. Tubuh manusia menghasilkan panas, yang menyebabkan peningkatan suhu dalam ruangan, sehingga menciptakan kondisi yang tidak nyaman. Selain itu, ruangan biasanya juga menyimpan peralatan listrik seperti komputer yang juga menghasilkan panas.

\subsubsection{Komponen Sistem}


Sistem kontrol yang digunakan dalam proyek penelitian ini terdiri dari rangkaian mikrokontroler yang disebut Arduino, sirkuit mikrokontroler yang disebut Raspberry Pi, sensor jarak ultrasonik, sensor inframerah pasif, sensor arus, jendela dan sensor status pintu, middleware, pemancar inframerah , AC, komponen analitik data, dan aplikasi untuk mengontrol sistem.

\subsubsection{Arduino}

Arduino adalah platform prototipe open-source berbasis pada perangkat keras dan lunak yang fleksibel dan mudah digunakan. Ini adalah mikrokontroler single-board, yang dirancang untuk membuat proses menggunakan elektronik dalam proyek multidisiplin lebih mudah. Konektor yang terekspos di Arduino memungkinkan prosesor untuk dihubungkan ke modul add-on. Arduino mampu berkomunikasi dengan perangkat lunak yang mengeksekusi pada komputer yang terhubung. Sistem Arduino mudah berinteraksi dengan komputer melalui USB ketika pemrograman diperlukan. Arduino di sisi lain tidak memiliki kemampuan penyimpanan permanen yang signifikan, tetapi kebanyakan menggabungkan RAM volatil. Arduino tidak bisa langsung terhubung baik ke monitor atau keyboard dan biasanya tidak meng-host sistem operasi. Di lingkungan laboratorium, dan aplikasi dunia nyata yang dibayangkan, Arduino di rumah pintar mendapatkan kode IR dari sensor di rumah. Kode-kode suhu naik, suhu turun, putar alat, dan putar alat ke bawah. Kode yang didapat kemudian disematkan ke Arduino untuk ditransmisikan ketika diperlukan.

\subsubsection{Raspberry Pi}

Raspberry Pi adalah komputer papan tunggal yang dikembangkan oleh yayasan Raspberry Pi. Ini menggunakan sistem operasi berbasis kernel Linux. Dibandingkan dengan komputer desktop, Raspberry Pi terbatas pada RAM dan daya CPU. Ini dapat dihubungkan ke monitor, keyboard dan mouse. Ini juga terhubung ke internet secara langsung dan memiliki fasilitas penyimpanan dan sistem operasi.

\subsubsection{Middleware}

Middleware adalah sistem yang memungkinkan komunikasi yang mudah antara hal-hal dan manusia melalui sejumlah protokol (atau saluran komunikasi) seperti email, Extensible Messaging dan Presence Protocol (XMPP), Hyper Text Transfer Protocol (HTTP), Facebook, Jabber (pesan instan ), MXit, Tag Identifikasi Frekuensi Radio (RFID), kode Quick response (QR), Short Messaging Service (SMS), Layanan Pesan Multimedia (MMS) dan Twitter. Komponen utama middleware adalah pengontrol. The middleware adalah antarmuka antara layanan bisnis dan saluran. Layanan bisnis ini dapat berkisar dari kalkulator, hingga tweet yang kembali pada tingkat bendungan atau suhu suatu objek, untuk penentuan tingkat kelembaban tanaman, dll. Permintaan layanan di middleware berasal dari pengguna melalui salah satu yang disebutkan di atas saluran. Mereka diarahkan melalui pengontrol ke layanan bisnis.

\subsubsection{Komponen Data Analytics}

Analisis data adalah proses pemeriksaan, pembersihan, transformasi, dan pemodelan data dengan tujuan menemukan informasi yang berguna, menyarankan kesimpulan dan mendukung pengambilan keputusan. Dalam hal ini sistem terus memonitor suhu ruangan sesuai dengan kehadiran orang-orang di ruangan dan sesuai dengan aturan tertentu, mengontrol AC. Suhu di kamar tetap konstan bahkan ketika jumlah orang di ruangan bervariasi. Informasi yang dihasilkan ditransmisikan ke mesin aturan yang kemudian memutuskan di mana untuk menyalakan atau mematikan AC.

\subsubsection{Aplikasi}

Komponen aplikasi mengandung aturan yang mengatur keputusan yang diambil pada kendali rumah pintar. Diperkirakan bahwa aplikasi juga akan menerima informasi dari utilitas listrik mengenai penyediaan listrik, dan informasi dari biro cuaca. Aplikasi kemudian membuat keputusan pada aturan 
seperti "Jika pintu ditutup dan jendela ditutup dan suhu di bawah tingkat tertentu, kemudian sesuaikan AC sesuai". Idealnya adalah pada akhirnya berada dalam posisi untuk mengendalikan seluruh lingkungan rumah pintar dengan cara ini.

\subsubsection{Arsitektur Sistem yang Mengontrol Penyejuk Udara di Ruangan}

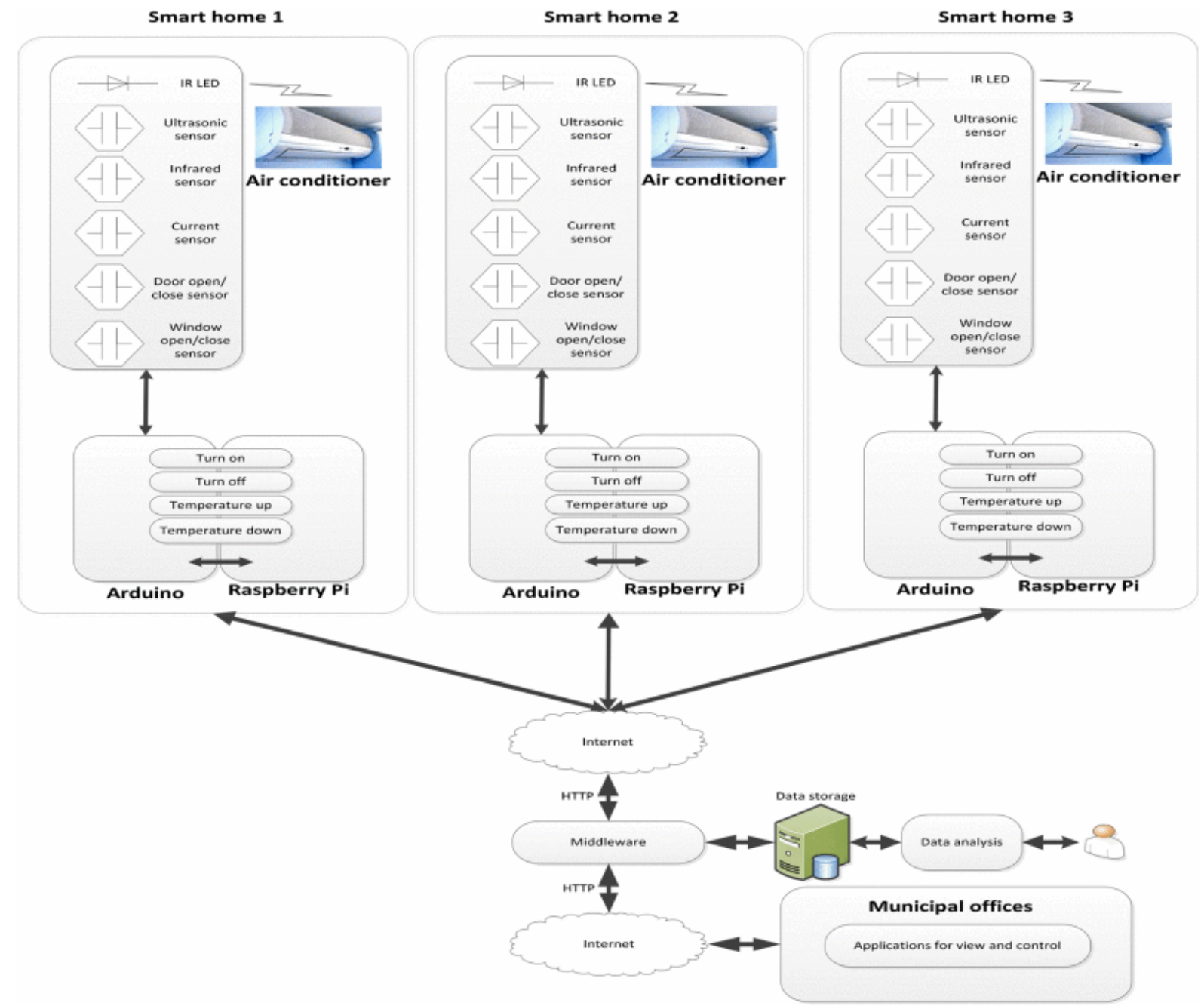

Gambar 1 : Ruang eksperimen terdiri dari sensor berikut, serta aktuator. 
- Sensor inframerah pasif untuk mendeteksi tubuh yang hangat setelah berada dalam jangkauan

- Sensor arus untuk mengukur konsumsi energi AC

- Sensor untuk mendeteksi apakah pintu / jendela terbuka atau tertutup

- Penyejuk udara yang dapat dihidupkan / dimatikan, atau suhunya dapat ditingkatkan atau diturunkan

Tujuannya agar sensor di rumah terhubung ke Arduino. Arduino pada gilirannya terhubung ke Raspberry Pi melalui kabel USB. Sepintas Arduino dan Raspberry Pi melakukan fungsi yang sama. Keduanya terhubung dengan dunia fisik. Perbedaannya adalah Raspberry Pi membutuhkan lebih banyak upaya dalam hal menyusun sirkuit elektronik untuk terhubung ke dunia fisik dibandingkan dengan Arduino. Fungsi Arduino dapat ditingkatkan dengan penambahan "perisai". Raspberry Pi, bagaimanapun, memiliki kekuatan pemrosesan yang cukup besar dibandingkan dengan Arduino. Raspberry Pi terhubung ke internet melalui kabel Ethernet, dan kemudian ke middleware. The middleware adalah perangkat lunak yang menerjemahkan antara protokol yang berbeda. Di sisi lain middleware adalah aplikasi yang mengkonsumsi data dan mengirim instruksi ke aktuator yang mengendalikan AC. Intelijen terletak pada aplikasi untuk pengambilan keputusan dan kontrol AC.

\section{KeSIMPULAN}

Makalah ini membahas penerapan IoT di kota-kota pintar. Penerapan ICT dalam layanan dan infrastruktur kota telah mengubah cara kota beroperasi dan memberikan layanan. Domain aplikasi untuk TIK di kota-kota pintar beragam mulai dari transportasi, pariwisata, kesehatan, lingkungan hidup dengan bantuan ambient, pencegahan kejahatan, tata kelola, infrastruktur, manajemen bencana, manajemen lingkungan, rumah pintar hingga energi cerdas.

\section{REFERENSI}

[1] Caragliu, A., Bo, C.D., Nijkamp, P., Smart cities in Europe, Journal of Urban Technology, Vol. 18, No. 2, 2011

[2] Dlodlo, N., Adopting the internet of things in environmental management in South Africa, 2nd International Conference on Environmental Science and Engineering ICESE 2012, Bangkok, Thailand, 2012

[3] Dlodlo, N., Mbecke, P., Mofolo, M., Mhlanga, M., The internet of things in community safety and crime prevention for South Africa, International Joint Conference on Computers, Information and Systems Sciences and Engineering CISSE 2013, University of Bridgeport, USA, 2013

[4] Fioroni, G., Pistore, M., Ranise, S., Amigoni, F., Caporusso, L., Gleria, F., Maffeis, A., Smart government: towards an innovative concept of a one-stop shop for interactive online services, IEEETN Smart Cities White Paper, Trento, Italy, 2014

[5] Harrison, C., Eckman, B., Hamilton, R., Hartswick, P., Kalagnanam, J., Paraszczak, J., Williams, P., Foundations of smarter cities, IBM Journal of research and development, Volume 54, No. 4. Pp. 1 16,2010

[6] Molinari, A., Maltese, V., Vaccari, L., Almi, A., Basssi, E., Big data and open data for a smart city, IEEE-TN Smart cities white papers, Trento, Italy, 2014

[7] Moreau, E., Towards smarter cities, Internal white paper v3.0, Dar Group, 2012 
[8] Nollo, G., Raffaeta, R., Caon, M., de Luca, A., Feliziani, C., Andrighettoni, P., Conci, N., Forti, S., Ravanelli, L., Gianordoli, M., Caprino, M., Torri, E., Conforti, D., Mion, L., Conci, M., Turra, E., IEEETN Smart cities White Paper, Trento, Italy, 2014

[9] Sensormind, an active framework for the internet of things, http://www.sensormind.net/en/ [10] Zanella, A., Vangelista, L., Internet of things for smart cities, IEEE Internet of Things journal, Volume 1, No. 1, 2014 